14,12

\title{
Светоизлучающие полевые транзисторы на основе композитных пленок полифлуорена и нанокристаллов $\mathrm{CsPBr}_{3}$
}

\author{
() А.Н. Алешин ${ }^{1}$, И.П. Щербаков ${ }^{1}$, Д.А. Кириленко ${ }^{1}$, Л.Б. Матюшкин ${ }^{2}$, В.А. Мошников ${ }^{2}$ \\ ${ }^{1}$ Физико-технический институт им. А.Ф. Иоффре, \\ Санкт-Петербург, Россия \\ ${ }^{2}$ Санкт-Петербургский государственный электротехнический университет „ЛЭТИ“, \\ Санкт-Петербург, Россия \\ E-mail: aleshin@transport.ioffe.ru
}

(Поступила в Редакцию 28 августа 2018 г.)

Получены светоизлучающие органические полевые транзисторы (СИ-ОПТ) на основе композитных пленок, состоящих из нанокристаллов перовскита $\left(\mathrm{CsPbr}_{3}\right)$ пленок, состоящих из нанокристаллов перовскита $\left(\mathrm{CsPbr}_{3}\right)$, внедренных в матрицу сопряженного полимера-полифлуорена (PFO), и исследованы их электрические и оптические свойства. Выходные и передаточные вольт-амперные характеристики (BAX) ОПТ на основе пленок $\mathrm{PFO}: \mathrm{CsPBBr}_{3}$ (соотношение компонентов 1:1) при температурах 100-300 K обладают незначительным гистерезисом и характерны для дырочного транспорта. Подвижность дырок при $250 \mathrm{~K}$ составляет $\sim 3.3 \mathrm{~cm}^{2} / \mathrm{Vs}$ и $\sim 1.9 \mathrm{~cm}^{2} / \mathrm{Vs}$ в режимах насыщения и низких полей соответственно и достигает $\sim 5 \mathrm{~cm}^{2} / \mathrm{Vs}$ при $100 \mathrm{~K}$. Показано, что приложение импульсного напряжения к СИ-ОПТ на основе $\mathrm{PFO}: \mathrm{CspBr}_{3}$ позволяет уменьшить ионную проводимость и обеспечить электролюминесценцию в такой структуре при $300 \mathrm{~K}$.

Исследования ПЭМ и ВР-ПЭМ проводились с использованием оборудования Федерального совместного научно-исследовательского центра „Материаловедение и характеристика в передовых технологиях“ при поддержке Министерства образования и науки Российской Федерации (ID RFMEFI62117X0018).

DOI: $10.21883 /$ FTT.2019.02.47142.244

\section{1. Введение}

Гибридные металлоорганические галогенидные перовскиты представляют собой новые растворимые материалы с уникальными электрическими и оптическими свойствами, включающими в себя способность к высоэффективному излучению света [1], высокие времена жизни и диффузионные длины носителей заряда [2,3], высокую подвижность [4-6], возможность перестройки ширины оптической запрещенной зоны (от видимой до ближней инфракрасной области) [4,7], а также возможность эмиссии белого света [8]. Солнечные элементы на основе металлоорганических галогенидных перовскитов демонстрируют эффективность преобразования солнечной энергии $\sim 23.3 \%$ (август 2018 г.) $[9,10]$; эти материалы перспективны для применения в фотодетекторах [11] и в светоизлучающих диодах [12-14]. Рассматриваемые материалы используются также в качестве полупроводниковых активных слоев в гибридных полевых транзисторах (ПТ) [15-17] и светоизлучающих полевых транзисторах (СИ-ПТ), архитектура которых совмещает в себе как переключающие, так и электролюминесцентные (ЭЛ) свойства перовскитов [6]. СИ-ПТ на основе металлоорганических галогенидных перовскитов обладают такими важными свойствами как высокая плотность носителей заряда, контролируемый ток через СИ-ПТ, инжекция носителей заряда, приводящая к эффективной ЭЛ, сопоставимой по интенсивности с органическими светодиодами [18]. Однако, несмотря на эти преимущества металлоорганических галогенидных перовскитов, они имеют ряд недостатков. В частности, на электронные свойства приборов на основе пленок металлоорганических перовскитов влияют такие факторы как: ионная проводимость [19], поляризационный беспорядок органических катионов [20], понижающие стабильность и надежность структур на их основе. Эти факторы, в частности, приводят к значительному гистерезису вольт-амперных характеристик (BАХ) ПТ [21] и низкой подвижности носителей заряда, которая на порядки ниже теоретических значений, а также к отсутствию полевого эффекта при комнатной температуре в перовскитных СИ-ПТ [6]. Ранее было показано, что ионный транспорт в основном обусловлен наличием ионных вакансий в перовските, что позволяет ионам перемещаться внутри кристаллической структуры материала [19]. Наиболее вероятным источником дрейфа ионов в йодиде свинца метиламмония является иодный анион, при этом катионы также могут принимать участие в транспорте. Было установлено, что разупорядочение, вызванное органическими катионами, обусловлено катионными дипольными флуктуациями [17], которые могут быть переориентированы при приложении электрического поля. В связи с этим было предположено, что ионы должны быть менее подвижны при низких температурах. Стабильность электрических свойств остается важнейшей проблемой для приборов на основе гибридных металлоорганических галогенидных перовскитов. Поэтому в последние годы большое внимание было уделе- 
но неорганическим перовскитам-нанокристаллам (НК) галогенидов свинца-цезия $\left(\mathrm{CsPb}_{3}, X=\mathrm{Cl}, \mathrm{Br}\right.$ и I), которые демонстрируют более высокую стабильность, способность к перестройке оптических свойств, а также высокий квантовый выход как фотолюминесценции (ФЛ) так и ЭЛ [22]. Однако проблема ионного транспорта остается актуальной и для структур на основе неорганических перовскитных НК [22,23]. Одним из возможных решений этой проблемы является использование гибридных материалов состоящих из неорганических перовскитных НК в матрице полупроводникового полимера. Предполагается, что такой композитный материал будет обладать свойствами как проводящих полимеров, так и перовскитных НК. Недавно нами были исследованы свойства НК перовскитов $\mathrm{CsPb}_{3}$ внедренных в матрицу полупроводникового полимера (PFO) [24]. Однако электрические и оптические свойства композитов и приборных структур на основе матрицы проводящего полимера (PFO) с НК другого галогенида свинца цезия, $\mathrm{CsPbr}_{3}$, до настоящего времени не исследовались.

В данной работе нами были получены и исследованы ОПТ на основе композитных пленок включающих в себя сопряженный полимер PFO и НК галогенида свинца цезия $\mathrm{CsPbBr}_{3}$. ОПТ на основе пленок $\mathrm{PFO}: \mathrm{CsPbBr}_{3}$ (соотношение компонентов $1: 1$ ) при температурах $100-300 \mathrm{~K}$ демонстрируют ВАХ, характерные для дырочного транспорта с незначительным гистерезисом выходных и передаточных характеристик. Подвижность дырок в таких структурах составила $\sim 3.3 \mathrm{~cm}^{2} / \mathrm{Vs}$ и $\sim 1.9 \mathrm{~cm}^{2} / \mathrm{Vs}$ в режимах насыщения и слабых электрических полей при $250 \mathrm{~K}$ и достигала $\sim 5 \mathrm{~cm}^{2} / \mathrm{Vs}$ при $100 \mathrm{~K}$. Показано, что режим работы СИ-ОПТ при приложении к истоку-стоку импульсного напряжения, позволяет уменышить гистерезис ВАХ, обусловленный ионной проводимостью в СИ-ОПТ на основе $\mathrm{PFO}: \mathrm{CsPbr}_{3}$ и обеспечить ЭЛ в такой структуре при комнатной температуре.

\section{2. Объекты и методы исследования}

В качестве полимерной матрицы был использован сопряженный полимер - Poly[9,9-bis-(2-ethylhexyl)-9Hfluorene-2,7-diyl] (PFO), с шириной запрещенной зоны $E_{g} \sim 2.7 \mathrm{eV}$, полученный от Sigma Aldrich и применявшийся в композитах без дополнительной обработки, при этом порошок PFO растворялся в толуоле. Нанокристаллы $\mathrm{CsPbBr}_{3}$ были синтезированы в октадекане методом горячей инжекции олеата цезия в раствор бромида свинца в смеси олеиновой кислоты, олеиламина и октадекана при $170^{\circ} \mathrm{C}$. Поверхность НК была стабилизирована олеиновой кислотой и молекулами олеиламина с отношением компонентов, идентичных протоколу синтеза, описанному в [25]. Рост НК бромистого свинца-цезия характеризуется короткими временами роста; синтез прекращался через $5 \mathrm{~s}$, затем частицы отделялись от раствора центрифугированием в присутствии изопропи-

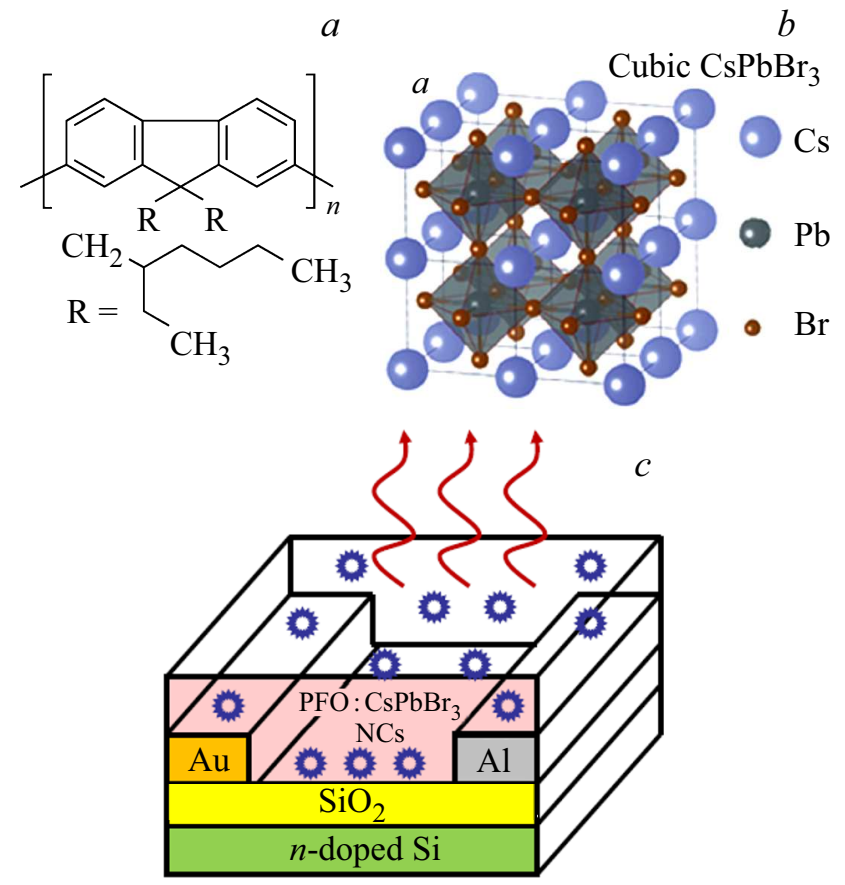

Рис. 1. Структура молекулы полимера $\mathrm{PFO}(a), \mathrm{CsPbBr}_{3}$ нанокристаллов $(b)$ и структура ОПТ на основе композитной пленки $\mathrm{PFO}: \mathrm{CsPbBr}_{3}(c)$.

лового спирта (объемное соотношение $1: 1$ ) и диспергировались в толуоле. НК $\mathrm{CsPbBr}_{3}$ имели кубическую форму с длиной грани $\sim 10 \mathrm{~nm}$ и $E_{g} \sim 2.7 \mathrm{eV}$, аналогично результатам, полученным в нашей предыдущей работе для $\mathrm{HK} \mathrm{CsPbI}_{3}$ [24].

На рис. 1 показаны структуры молекул полимера PFO $(a)$ и НК перовскита-галогенида свинца цезия $\mathrm{CsPbBr}_{3}$ (b). Нами были получены ОПТ структуры на основе композитных пленок $\mathrm{PFO}: \mathrm{CsPbBr}_{3}$ (HК) вида $n-\mathrm{Si} / \mathrm{SiO}_{2} / \mathrm{Au} / \mathrm{PFO}: \mathrm{CsPbBr}_{3}(\mathrm{HK}) / \mathrm{Al}(\mathrm{Au})$ (рис. 1, 1 ). В качестве затвора использовалась подложка из сильно легированного $n^{+}$кремния $(\mathrm{Si})$ со слоем $\mathrm{SiO}_{2}$, полученного термическим окислением $\mathrm{Si}$, толщиной $200 \mathrm{~nm} \mathrm{в} \mathrm{качестве} \mathrm{диэлектрика,} \mathrm{на} \mathrm{который} \mathrm{термиче-}$ ским напылением наносились золотые $(\mathrm{Au})$ и алюминиевые (Al) электроды. Расстояние между $\mathrm{Au}-\mathrm{Al}$ и $\mathrm{Au}-\mathrm{Au}$ электродами составляло $\sim 7 \mu \mathrm{m}$ и $\sim 15 \mu \mathrm{m}$ соответственно, а ширина электродов $\sim 1 \mathrm{~mm}$. Порошки PFO-полимера и НК $\mathrm{CsPbBr}_{3}$ соответственно растворяли и диспергировали в толуоле. Растворы смешивали при относительной концентрации PFO и $\mathrm{CsPbBr}_{3} \mathrm{HK} 1: 1$. Полученную смесь наносили на $\mathrm{Si} / \mathrm{SiO}_{2}$ подложки с $\mathrm{Au}$ и $\mathrm{Al}$ электродами методами полива или центрифугирования (при $3000 \mathrm{rpm}$ ). Осажденные композитные пленки сушили при $100^{\circ} \mathrm{C}$ в атмосфере азота в течение $15 \mathrm{~min}$. Толщина композитных пленок, нанесенных методом полива, составляла около $0.6 \mu \mathrm{m} \mathrm{в}$ соответствии с результатами атомно-силовой микроскопии. Исследования образцов методами просвечива- 
ющей электронной микроскопии (ПЭМ) и просвечивающей электронной микроскопии высокого разрешения (ВР-ПЭМ) проводились с использованием микроскопа Jeol JEM-2100F с ускоряющим напряжением $200 \mathrm{kV}$ и разрешением между точками $0.19 \mathrm{~nm}$. Образцы для ПЭМ-исследований получали путем смачивания медной сетки ПЭМ, покрытой ультратонкой графеновой бумагой [26] в суспензии НК. Спектры поглощения образцов, осажденных методом полива на кварцевые подложки, регистрировали с использованием спектрометра Cary-50 (Varian). Спектры ФЛ пленок $\mathrm{PFO}, \mathrm{CsPbBr}_{3}$ и $\mathrm{PFO}: \mathrm{CsPBr}_{3}$ возбуждались ультрафиолетовым светодиодом UVTOP280TO39HS с длиной волны излучения $285 \mathrm{~nm}$. Светодиодное излучение проходило через ультрафиолетовый фильтр UFS-8 и фокусировалось на поверхности образцов с использованием кварцевой линзы под углом $\sim 10^{\circ}$ к нормали поверхности образца в пятно диаметром $\sim 2 \mathrm{~mm}$. Спектры ФЛ регистрировались высокочувствительным оптоволоконным спектрометром „AVANTES“ - AvaSpec-ULSi2048L-USB2 OEM, работающим в спектральном диапазоне $322-1100 \mathrm{~nm}$ со спектральным разрешением $4 \mathrm{~nm}$. Временные характеристики интенсивности ЭЛ, наблюдаемой при подаче импульсного смещения на светоизлучающие структуры, измерялись с помощью фотоумножителя со спектральной чувствительность в интервале $300-850 \mathrm{~nm}$. Выходные и передаточные ВАХ ОПТ на основе пленок $\mathrm{PFO}: \mathrm{CsPbBr}_{3}$ измерялись в атмосфере азота, в темноте, при температурах $100-300 \mathrm{~K}$ с использованием азотного $\left(\mathrm{N}_{2}\right)$ оптического криостата орtCRYO198 с функцией стабилизации температуры и электронной автоматизированной измерительной системы на основе пикоамперметра Keithley 6487 и программируемого источника напряжения AKIP-1124. Напряжение на стоке-истоке и затворе ОПТ варьировалось в пределах от $-20 \mathrm{~V}$ до $+20 \mathrm{~V}$ с переменным шагом. Электрические контакты к образцам выполнялись серебряной проволокой с использованием проводящих углеродных или серебряных паст. Подвижность носителей заряда, $\mu_{\mathrm{FET}}$, в $\mathrm{PFO}: \mathrm{CsPbBr}_{3}$ ОПТ оценивалась из ВАХ в режимах насыщения и слабых электрических полей соответственно, используя выражения [27]:

$$
\begin{gathered}
I_{\mathrm{SD}}=(W / 2 L) \mu_{\mathrm{FET}} C_{\mathrm{I}}\left(V_{\mathrm{G}}-V_{\mathrm{th}}\right)^{2} \\
I_{\mathrm{SD}}=(W / L) \mu_{\mathrm{FET}} C_{\mathrm{I}}\left(V_{\mathrm{G}}-V_{\mathrm{th}}\right) V_{\mathrm{SD}},
\end{gathered}
$$

где $W$ - ширина канала, $L-$ длина канала, $C_{\mathrm{I}}-$ емкость на единицу площади $\mathrm{SiO}_{2}$ (толщина $\sim 200 \mathrm{~nm}$, $\left.C_{\mathrm{I}} \sim 10 \mathrm{nF} / \mathrm{cm}^{2}\right), V_{\mathrm{G}}-$ напряжение на затворе, $V_{\mathrm{th}}-$ пороговое напряжение соответствующее началу режима насышения. $V_{\text {th }}$ определялось из передаточных характеристик при использовании линейной аппроксимации зависимости $V_{\mathrm{SD}}^{0.5}$ от $V_{\mathrm{G}}$. Импульсное напряжение подавалось при помощи низкочастотного генератора сигналов Г3-56/1. Амплитуда импульсов напряжения варьировалась между $+85 \mathrm{~V}$ и $-85 \mathrm{~V}$ при частоте импульсов $12 \mathrm{kHz}$, при длительности импульсов - $10 \mu \mathrm{s}$.

\section{3. Результаты и обсуждение}

Результаты ПЭМ и ВР-ПЭМ исследований перовскитных $\mathrm{CsPbBr}_{3}$ НК представлены на рис. 2, $a$ и $b$. Как видно из рис. 2, $a$ и $b$, монодисперсные $\mathrm{CsPbBr}_{3}$ НК имеют средний диаметр $\sim 8-10 \mathrm{~nm}$ с кубической формой, определяемой кристаллической структурой пе-

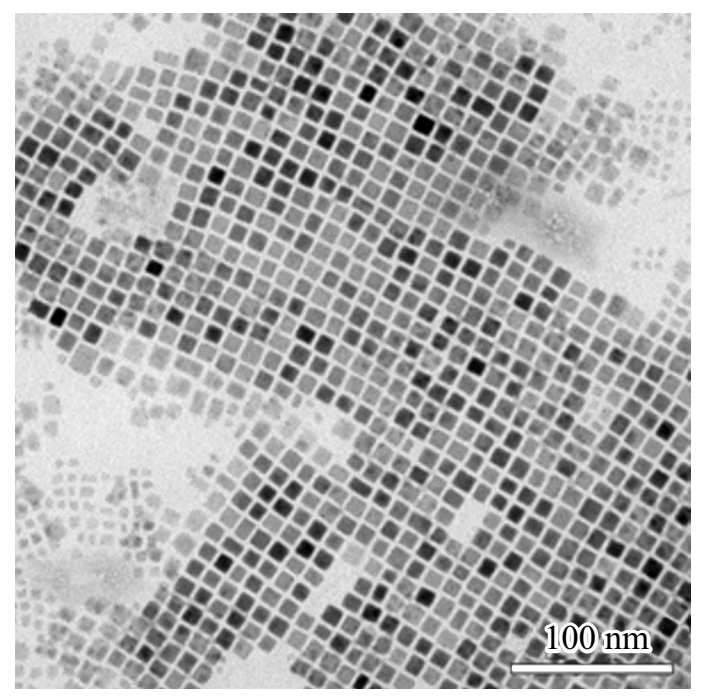

$a$

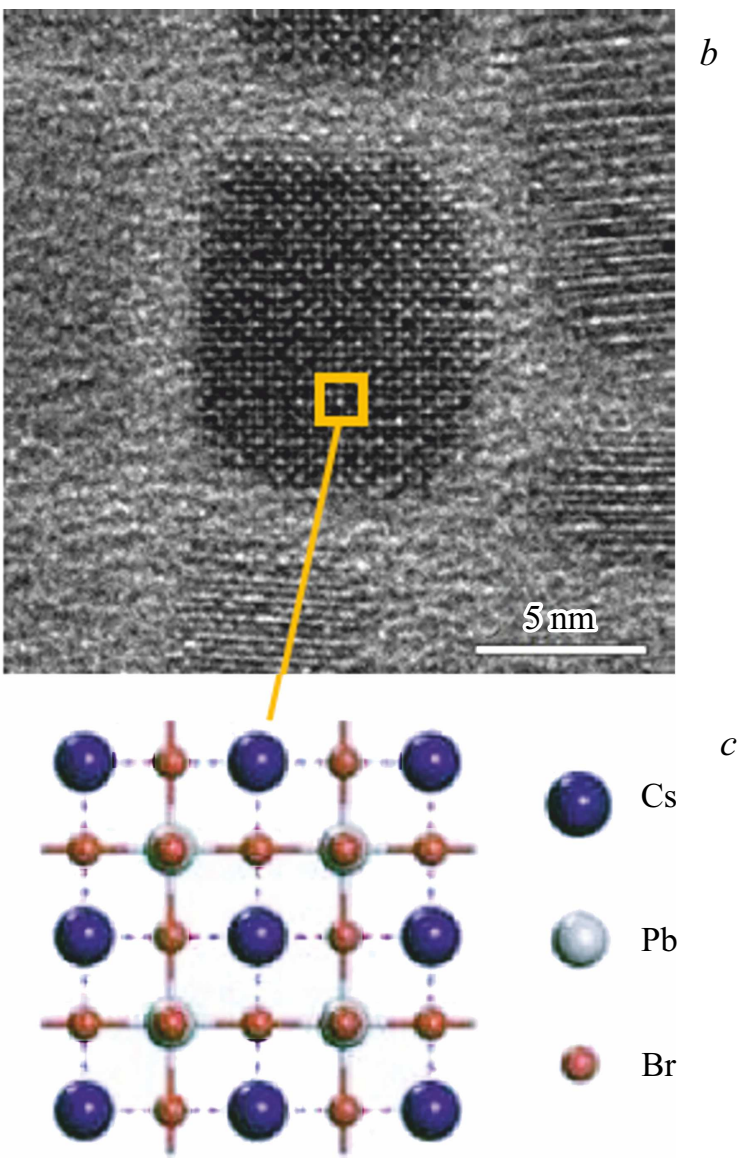

Рис. 2. Результаты ПЭМ (a) и ВР-ПЭМ (b) исследований монодисперсных слоев НК перовскита $\mathrm{CsPbBr}_{3}$. 


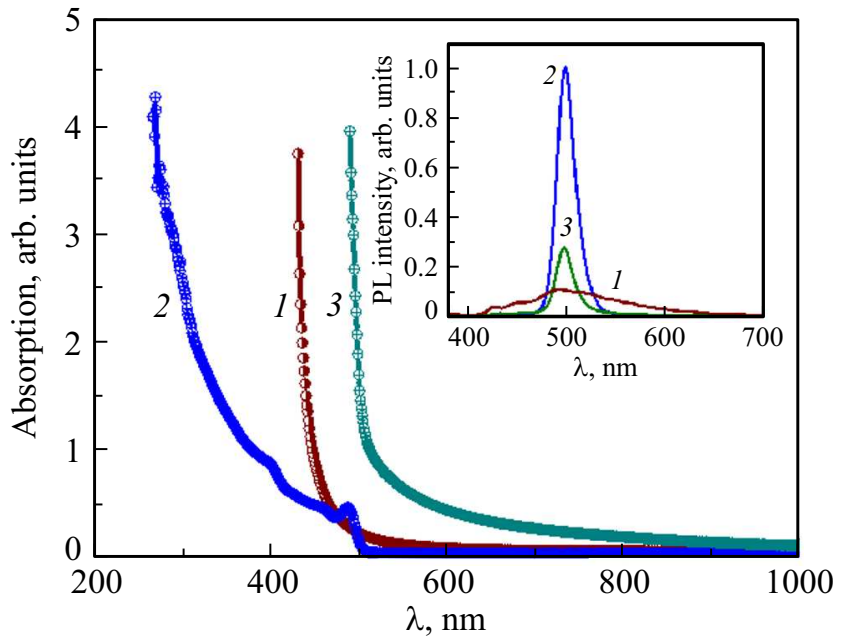

Рис. 3. Спектры поглощения и ФЛ (вставка) пленок PFO (1), $\mathrm{CsPbBr}_{3} \mathrm{HK}$ (2) и $\mathrm{PFO}: \mathrm{CsPbBr}_{3}(1: 1)$ (c) на кварцевых подложках. Спектр ФЛ полимера РFO умножен на 50.

ровскита. Результаты ПЭМ и ВР-ПЭМ, показанные на рис. $2, a$ и $b$, подтверждают, что $\mathrm{Cs} \mathrm{PbBr}$ НК имеют очень хорошую кристалличность, что является важным условием для повышения эффективности ФЛ и ЭЛ светоизлучающих устройств. Изображение ВР-ПЭМ (рис. 2, $b$ ) демонстрирует кубическую кристаллическую решетку $\mathrm{HK} \mathrm{CsPbr}_{3}$, что дополнительно подтверждают высокое качество НК, при этом конфигурация атома находится в хорошем соответствии с кубической кристаллической структурой НК $\mathrm{CsPbBr}_{3}$. Полученные результаты ПЭМ и ВР-ПЭМ хорошо согласуются с данными для НК $\mathrm{CsPbr}_{3}$, полученными другими авторами [28].

Типичные спектры поглощения и ФЛ пленок PFO (1), $\mathrm{CsPbBr}_{3} \mathrm{HK}$ (2) и композита $\mathrm{PFO}: \mathrm{CsPbBr}_{3}$ (1:1) (3), нанесенных на кварцевые подложки, показаны на рис. 3 и на вставке к рис. 3. Как следует из рис. 3, спектры поглощения пленок $\mathrm{PFO}, \mathrm{CsPbr}_{3}$ и $\mathrm{PFO}: \mathrm{CsPbBr}_{3}$ лежат в спектральной области $\sim 300-550 \mathrm{~nm}$, что хорошо согласуется с шириной запрещенной зоны полимера $\mathrm{PFO}$ $\left(E_{g} \sim 2.7 \mathrm{eV}\right)$ и НК $\mathrm{CsPbBr}_{3}\left(E_{g} \sim 2.75 \mathrm{eV}\right)$. Вставка на рис. 3 показывает, что спектры ФЛ тех же пленок лежат в спектральной области $\sim 400-650 \mathrm{~nm}$ с максимумами при $\lambda \sim 490-500 \mathrm{~nm}$, что соответствует положениям края поглощения $\mathrm{PFO}$ и $\mathrm{CsPbr}_{3}$ НК. Как следует из вставки на рис. 3, интенсивность ФЛ тонких пленок $\mathrm{CsPbBr}_{3} \mathrm{HK}$ (2) и композитов $\mathrm{PFO}: \mathrm{CsPbBr}_{3}(1: 1)$ (3) очень велика, что свидетельствует о высокой квантовой эффективности ФЛ перовскитных НК $\mathrm{CsPbBr}_{3}$ [22,23].

На рис. 4, $a-c$ представлены выходные и передаточные BAX на постоянном токе для ОПТ на основе пленок $\mathrm{PFO}: \mathrm{CsPbr}_{3}(1: 1)$ c $\mathrm{Au}-\mathrm{Al}$ электродами в качестве стока-истока при различных температурах и при различных напряжениях на затворе $\left(V_{\mathrm{G}}\right)$. Как следует из рис. 4, $a$ и $b$, выходные $\mathrm{BAX}$ для $\mathrm{PFO}: \mathrm{CsPbr}_{3}$ ОПТ при $T=250 \mathrm{~K}$ и $100 \mathrm{~K}$ имеют вид характерный для преобладающего дырочного транспорта в ОПТ в режиме насыщения. Отметим, что ОПТ на основе пленок $\mathrm{PFO}: \mathrm{CsPbr}_{3}$ работает при достаточно низких
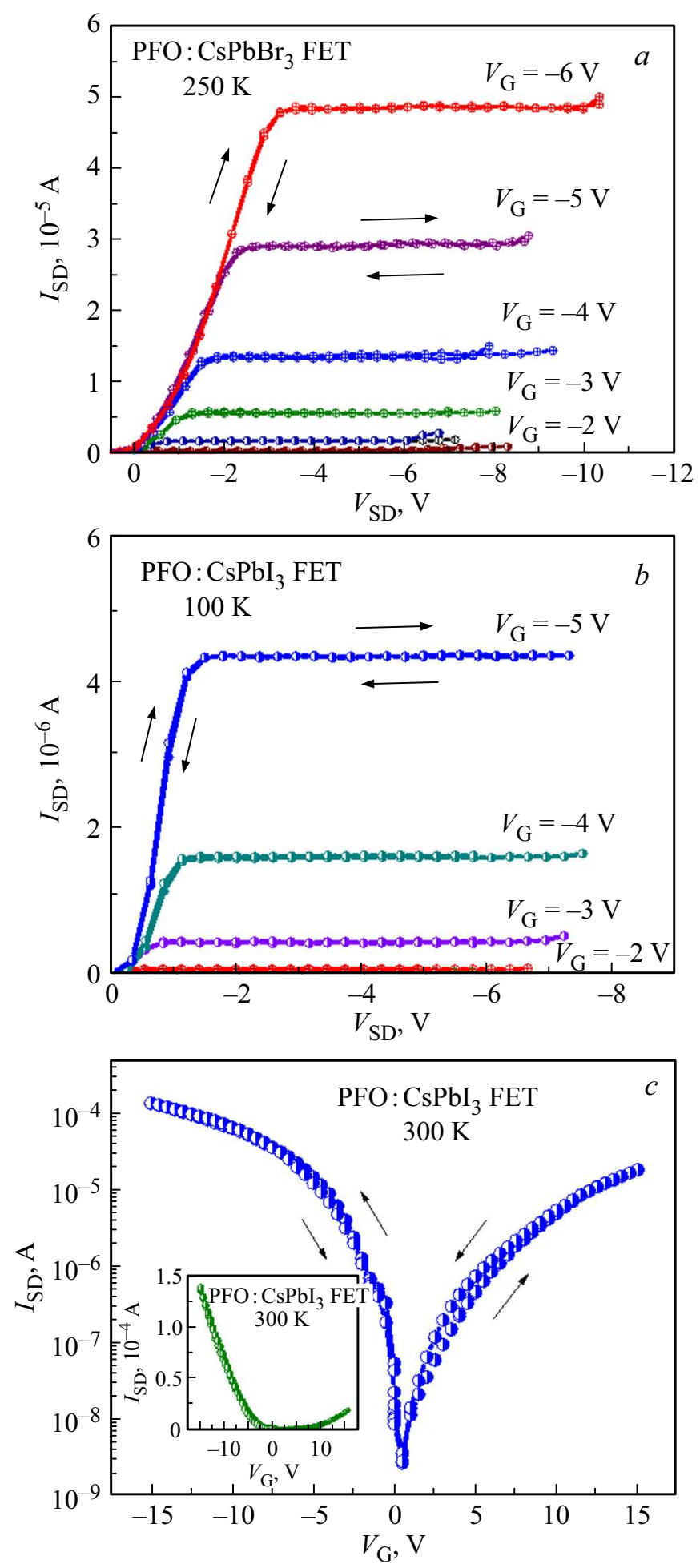

Рис. 4. Выходные BAX PFO: $\mathrm{CsPbBr}_{3}$ OПТ (1:1) измеренные в темноте, при отрицательных значениях $V_{\mathrm{G}}$ при различных температурах, К: a) 250; b) 100; c) передаточные характеристики PFO: $\mathrm{CsPbBr}_{3}$ OПТ при $V_{\mathrm{SD}}=-6 \mathrm{~V}$ измеренные в темноте, при $300 \mathrm{~K}$. Вставка: $I_{\mathrm{SD}}$ vs $V_{\mathrm{G}}$ для того же ОПТ при $300 \mathrm{~K}$. 


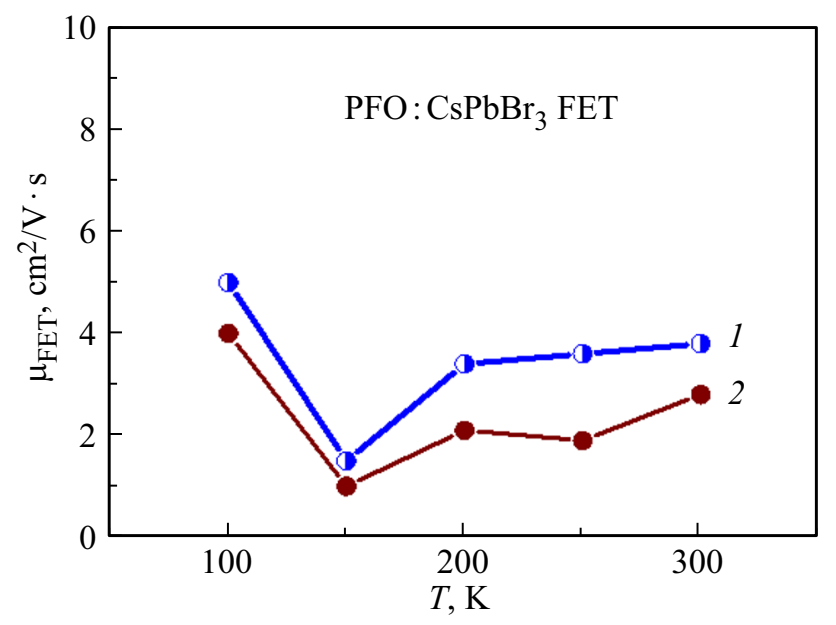

Рис. 5. Температурные зависимости подвижности дырок для $\mathrm{PFO}: \mathrm{CsPbBr}_{3}$ OПТ $(1: 1)$ в режимах насыщения (1) и слабых полей (2).

напряжениях на стоке-истоке $\left(V_{\mathrm{SD}}\right)$ и затворе $V_{\mathrm{G}}$ (ниже $\sim 15 \mathrm{~V})$. На рис. $4, b$ показаны типичные передаточные BAX с незначительным гистерезисом при $T=300 \mathrm{~K}$ для того же $\mathrm{PFO}: \mathrm{CsPbr}_{3}$ OПТ, измеренные в темноте при отрицательных и положительных значениях $V_{\mathrm{G}}$ от $-15 \mathrm{~V}$ до $+15 \mathrm{~V}$ и при $V_{\mathrm{SD}}=-6 \mathrm{~V}$. Как следует из pис. 4, , ОПТ на основе пленок $\mathrm{PFO}: \mathrm{CsPb}_{3}$ работает в основном в режиме накопления дырок, то есть преимущественно в униполярном режиме. Как видно из рис. 4, $a-c$, гистерезис выходных и передаточных характеристик PFO: $\mathrm{CsPbBr}_{3}$ OПТ при $T=300 \mathrm{~K}$ незначителен и уменьшается при низких температурах, что может указывать на уменьшение ионного дрейфа в матрице полимера PFO. Таким образом, понижение температуры ниже $250 \mathrm{~K}$ приводит к уменьшению ионного транспорта в композитных пленках $\mathrm{PFO}: \mathrm{CsPbBr}_{3}$, что приводит к уменьшению гистерезиса ВАХ ОПТ. Отношения ON/OFF, рассчитанные из передаточных характеристик, показанных на рис. 4, $c$, составили для дырок $\sim 10^{5}$ при $V_{\mathrm{G}}=-15 \mathrm{~V}$. Подвижность дырок, $\mu_{\mathrm{h}}$, для ОПТ на основе пленок $\mathrm{PFO}: \mathrm{CsPbr}_{3}$ была рассчитана с использованием уравнений (1) и (2) для режимов насыщения и слабых электрических полей, соответственно. Для $\mathrm{PFO}: \mathrm{CsPbr}_{3}$ ОПТ с ВАХ, представленных на рис. 4, $a-c$, величина порогового напряжения, $V_{\mathrm{th}}$, оцененная при $250 \mathrm{~K}$ из наклона зависимости $I_{\mathrm{SD}}^{0.5}$ от $V_{\mathrm{G}}$ при $V_{\mathrm{SD}}=-6 \mathrm{~V}$, была $\sim 0.8 \mathrm{~V}$ при отрицательных $V_{\mathrm{G}}$. Как показано на рис. 5, расчетная подвижность дырок при $250 \mathrm{~K}$ составила $\sim 3.3 \mathrm{~cm}^{2} / \mathrm{Vs}$ и $\sim 1.9 \mathrm{~cm}^{2} / \mathrm{Vs}$ в режимах насыщения и слабых полей соответственно; при $150 \mathrm{~K}$ она достигала минимальных значений $\sim 1.5 \mathrm{~cm}^{2} / \mathrm{Vs}$ и $\sim 1 \mathrm{~cm}^{2} / \mathrm{Vs}$ соответственно, а затем возрастала до $\sim 5 \mathrm{~cm}^{2} / \mathrm{Vs}$ при понижении температуры до $100 \mathrm{~K}$. Такое поведение $\mu_{\mathrm{FET}}(T)$ напоминает температурную зависимость подвижности в СИ-ОПТ на основе пленок гибридных (органиканеорганика) галогенидных перовскитов $\mathrm{CH}_{3} \mathrm{NH}_{3} \mathrm{PbI}_{3}$ [6], но в нашем случае значения $\mu_{\mathrm{FET}}$ при $300 \mathrm{~K}$ оказались выше на два порядка, по сравнению со значениями $\mu_{\mathrm{FET}}$, полученными в [6] и на порядок выше, чем в $\mathrm{PFO}: \mathrm{CsPbI}_{3}$ OПТ [24]. Наблюдаемое в $\mathrm{PFO}: \mathrm{CsPbBr}_{3}$ ОПТ значительное увеличение полевой подвижности как при $300 \mathrm{~K}$, так и при низких температурах может быть связано с целым рядом факторов, обусловленных уменьшением влияния миграции ионов из-за множественных гетеропереходов в гибридной (полимер-НК) структуре, а также со снижением концентрации заряженных точечных дефектов, расположенных на границах $\mathrm{HK} \mathrm{CsPbBr}_{3}$, и, кроме того, с уменьшением поляризационной разупорядоченности дипольных моментов $\mathrm{Cs}^{+}$катионов при $300 \mathrm{~K}$ и снижением амплитуды тепловых колебаний цезиевых галогенидов [17]. Минимум в температурной зависимости подвижности дырок, наблюдаемый при $\sim 150 \mathrm{~K}$, может быть связан со снижением экранирующих эффектов, обусловленных ионным переносом цезиевых катионов. Подобное поведение зависимости подвижности от температуры было получено для нескольких других образцов $\mathrm{PFO}: \mathrm{CsPbBr}_{3}$ ОПТ с темновыми токами порядка $\sim 10^{-9}$ А, при измерении BAX в атмосфере азота. Таким образом, полученные результаты указывают на то, что понижая температуру $\mathrm{PFO}: \mathrm{CsPbBr}_{3}$ OПТ до $T \sim 100 \mathrm{~K}$, можно уменьшить эффекты ионного транспорта, и, следовательно, добиться более сбалансированного переноса заряда и более высокой подвижности.

Стоит отметить, что в композитных (органика-неорганика) металлоорганических галогенидных перовскитных ОПТ и СИ-ОПТ [6], работающих при приложении постоянного смещения, дырки и электроны непрерывно инжектируются навстречу друг другу в канал ОПТ из истока и стока, что приводит к появлению узкой зоны рекомбинации носителей, положением которой можно управлять путем изменения смещения на стоке-истоке и затворе. В то же время приложение постоянного смещения приводит к заметной миграции ионов и поляризации $\mathrm{Cs}^{+}$катионов в перовскитных НК. Как было показано в [6], приложение высокочастотных (или импульсных) смещений препятствует ионной миграции и поляризации катионов метиламмония (или Cs) при относительно высоких частотах, которые должны быть выше, чем времена отклика процессов ионной миграции. На рис. 6, $a$ и $b$, а также на рис. 7 показан эффект ЭЛ из $\mathrm{PFO}: \mathrm{CsPbBr}_{3}(1: 1) \mathrm{CИ}-\mathrm{OПТ} \mathrm{при} \mathrm{приложении} \mathrm{отри-}$ цательных импульсных смещений к истоку-стоку при 300 К. Как упоминалось ранее, светоизлучающий эффект в СИ-ОПТ на основе металлоорганических галогенидных перовскитов $\mathrm{CH}_{3} \mathrm{NH}_{3} \mathrm{PbI}_{3}$ наблюдался только при температурах ниже $200 \mathrm{~K}$ [6]. В случае $\mathrm{PFO}: \mathrm{CsPbBr}_{3}$ СИ-ОПТ при приложении отрицательных импульсных смещений к электродам исток-сток $(\mathrm{Au}-\mathrm{Al})$ наблюдается значительная ЭЛ при комнатной температуре, как показано на рис. 6,a. Формы возбуждающего импульса напряжения $\left(V_{\mathrm{SD}}=-75 \mathrm{~V}\right.$, длительность импульса $\sim 10 \mu \mathrm{s})$ и импульсной ЭЛ пленок $\mathrm{PFO}: \mathrm{CsPbr}_{3}$ показаны на рис. $6, b$ и 7. Как видно из рис. $6, a$, в СИ-ОПТ 

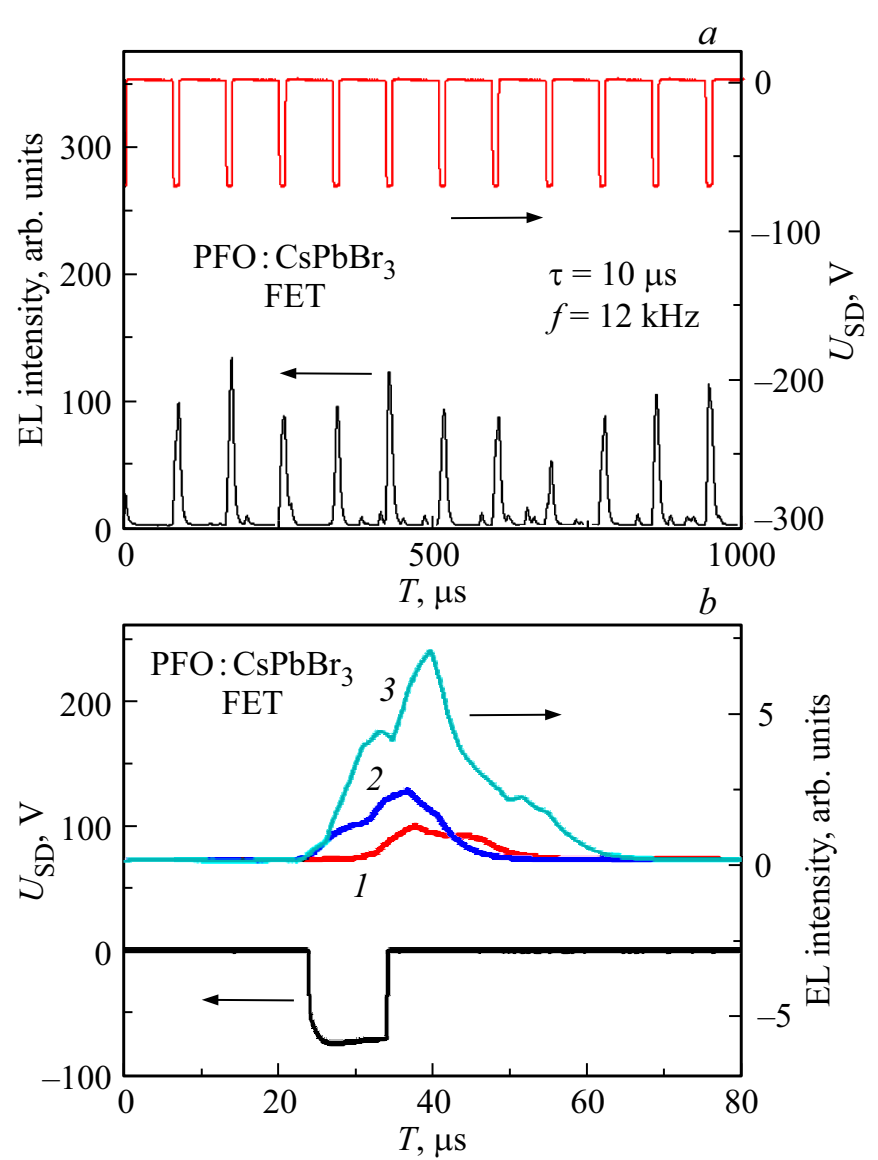

Рис. 6. $a-$ импульсная ЭЛ при приложении импульсного $V_{\mathrm{SD}}$ для $\mathrm{PFO}: \mathrm{CsPbBr}_{3}$ СИ-ОПТ $(1: 1)$ при $f=12 \mathrm{kHz}$ и $V_{\mathrm{SD}}=-75 \mathrm{~V}$. Длительность импульса $10 \mu \mathrm{s} . b-$ временные зависимости импульсной ЭЛ для $\mathrm{PFO}: \mathrm{CsPbBr}_{3}(1: 1)$ СИ-ОПТ $\left(f=12 \mathrm{kHz}, V_{\mathrm{SD}}=-75 \mathrm{~V}\right)$ при различных $V_{\mathrm{G}}, \mathrm{V}: 1-0$; $2--5 ; 3--9$. СИ-ОПТ излучает свет только при отрицательных импульсных смещениях $V_{\mathrm{SD}}$ и при отрицательных $V_{\mathrm{G}}$.

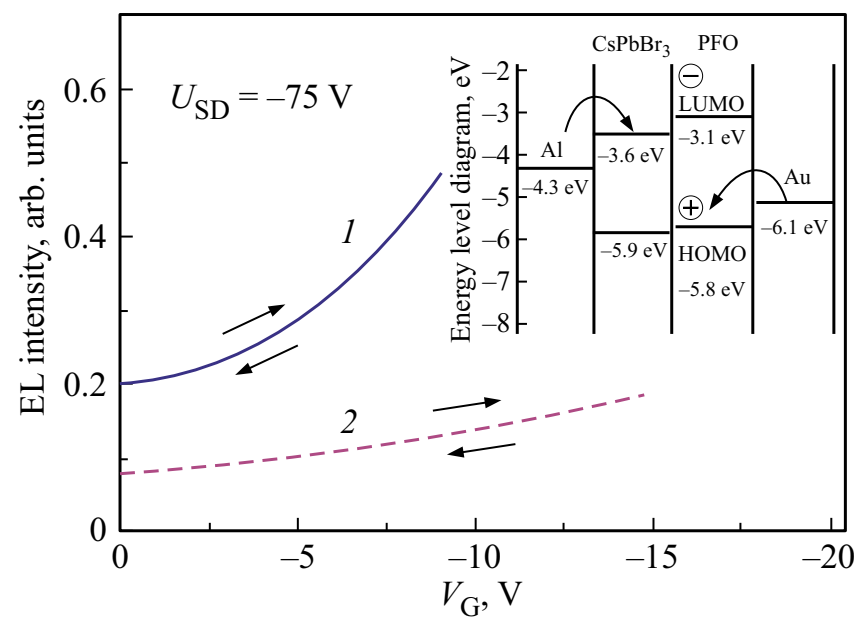

Рис. 7. Интенсивность ЭЛ при импульсном возбуждении в зависимости от $V_{\mathrm{G}}$ для $\mathrm{PFO}: \mathrm{CsPbBr}_{3}$ (1) и $\mathrm{PFO}: \mathrm{CsPbI}_{3}$ (2) [24] СИ-ОПТ при приложении импульсного $V_{\mathrm{SD}}=-75 \mathrm{~V}$. Вставка: зонная диаграмма структуры $\mathrm{Al} / \mathrm{PFO} / \mathrm{CsPBr}_{3} / \mathrm{Au}$. на основе пленок $\mathrm{PFO}: \mathrm{CsPbr}_{3}$ управляемый импульсными смещениями на истоке-стоке, наблюдается ЭЛ только при приложении отрицательного импульсного смещения. Как видно из рис. $6, b$, интенсивность ЭЛ СИ-ОПТ на основе $\mathrm{PFO}: \mathrm{CsPbBr}_{3}$ при импульсном режиме смещения $V_{\mathrm{SD}}(f=12 \mathrm{kHz})$ возрастает по мере увеличения смещения на затворе от $0 \mathrm{~V}$ до $-9 \mathrm{~V}$. Наблюдаемые пики ЭЛ при приложении отрицательных импульсов напряжения являются достаточно резкими, а их вклад в интегрированную по времени интенсивность ЭЛ является значительным. Зависимость интенсивности ЭЛ $\mathrm{PFO}: \mathrm{CsPbr}_{3} \mathrm{CИ}-\mathrm{OПТ}$ от приложенного смещения на затворе $V_{\mathrm{G}}$ является сверхлинейной и более сильной, чем у $\mathrm{PFO}: \mathrm{CsPbI}_{3} \mathrm{CИ}-\mathrm{OПT}$, полученной в [24] при том же импульсном режиме смещения $V_{\mathrm{SD}}$, как показано на рис. 7. Важно отметить отсутствие гистерезиса в зависимостях интенсивности ЭЛ от смещения на затворе при проведении нескольких циклов таких измерений.

На вставке на рис. 7 показана зонная диаграмма исследованной нами структуры $\mathrm{Al} / \mathrm{PFO} / \mathrm{CsPbBr}_{3} / \mathrm{Au}$. Из анализа зонной диаграммы следует, что механизм образования возбужденных состояний в композитных пленках $\mathrm{PFO}: \mathrm{CsPbBr}_{3}$ подразумевает наличие излучательного рекомбинационного канала LUMO-HOMO в полимере PFO, включая рекомбинацию экситонов; вклад от канала излучательной рекомбинации зона-зона в $\mathrm{HK} \mathrm{CsPbBr}_{3}$, включая примесные уровни, а также канал безызлучательной передачи энергии по механизму Ферстера между обоими компонентами композита из-за перекрытия спектров поглощения PFO и спектров ФЛ $\mathrm{CsPbBr}_{3}$ HК [29]. В нашем случае наблюдаемая ЭЛ определяется дырками, инжектированными при приложении отрицательного импульсного смещения из истока и их рекомбинацией с электронами в активном слое $\mathrm{PFO}: \mathrm{CsPbr}_{3}$, при этом рекомбинация происходит как вблизи электродов, так и внутри канала. Увеличение интенсивности ЭЛ при приложении отрицательных импульсов напряжения к истоку-стоку ОПТ на основе пленок PFO: $\mathrm{CsPBr}_{3}$, как и в случае стационарной ЭЛ, также подразумевает, что инжекция носителей заряда (дырок) из истока и затвора и их дальнейший транспорт через канал ОПТ, является основным механизмом транспорта в таких ОПТ. Различие в работах выхода двух инжектирующих электродов приводит к несимметричным ВАХ СИ-ОПТ, что обуславливает тот факт, что ЭЛ наблюдается только при приложении отрицательного импульсного смещения.

\section{4. Заключение}

Нами получены и исследованы СИ-ОПТ на основе композитных пленок, состоящих из НК перовскита $\mathrm{CsPbBr}_{3}$, внедренных в матрицу сопряженного полимера PFO. Выходные и передаточные ВАХ ОПТ на основе пленок $\mathrm{PFO}: \mathrm{CsPbBr}_{3}(1: 1)$ при температурах $100-300 \mathrm{~K}$ обладают незначительным гистерезисом и 
характерны для дырочного транспорта. Подвижность дырок при $250 \mathrm{~K}$ составляет $\sim 3.3 \mathrm{~cm}^{2} / \mathrm{Vs} ~ \sim 1.9 \mathrm{~cm}^{2} / \mathrm{Vs}$ в режимах насыщения и слабых электрических полей соответственно и возрастает до $\sim 5 \mathrm{~cm}^{2} / \mathrm{Vs}$ при $100 \mathrm{~K}$. Показано, что режим работы СИ-ОПТ на основе $\mathrm{PFO}: \mathrm{CsPbr}_{3}$, заключающийся в приложении импульсного напряжения к истоку-стоку, позволяет уменьшить ионную проводимость и обеспечить ЭЛ в такой структуре при комнатной температуре.

Авторы благодарны И.Н. Трапезниковой за помощь в измерении спектров поглощения.

\section{Список литературы}

[1] F. Deschler, M. Price, S. Pathak, L.E. Klintberg, D.-D. Jarausch, R. Higler, S. Hüttner, T. Leijtens, S.D. Stranks, H.J. Snaith, M. Atatüre, R.T. Phillips, R.H. Friend. J. Phys. Chem. Lett. 5, 1421 (2014).

[2] S.D. Stranks, G.E. Eperon, G. Grancini, C. Menelaou, M.J.P. Alcocer, T. Leijtens, L.M. Herz, A. Petrozza, H.J. Snaith. Science 342, 341 (2013).

[3] Y. Chen, H.T. Yi, X. Wu, R. Haroldson, Y.N. Gartstein, Y.I. Rodionov, K.S. Tikhonov, A. Zakhidov, X.Y. Zhu, V. Podzorov. Nature Commun. 7, 12253 (2016).

[4] C.C. Stoumpos, C.D. Malliakas, M.G. Kanatzidis. Inorganic Chem. 52, 9019 (2013).

[5] C. Motta, F. El-Mellouhi, S. Sanvito. Sci. Rep. 5, 12746 (2015).

[6] X.Y. Chin, D. Cortecchia, J. Yin, A. Bruno, C. Soci. Nature Commun. 6, 7383 (2015).

[7] J.H. Heo, S.H. Im, J.H. Noh, T.N. Mandal, C.-S. Lim, J.A. Chang, Y.H. Lee, H.J. Kim, A. Sarkar, Md.K. Nazeeruddin, M. Gratzel, S.I. Seok. Nature Photon. 7, 486 (2013).

[8] D. Cortecchia, J. Yin, A. Bruno, S.-Z.A. Lo, G.G. Gurzadyan, S. Mhaisalkar, J.-L. Bredas, C. Soci. J. Mater. Chem. C 5, 2771 (2017).

[9] National Renewable Energy Laboratory, Best Research Cell Efficiencies. www.nrel.gov/ncpv/images/efficiency_chart.jpg; accessed: August 2018.

[10] M.A. Green, A. Ho-Baillie, H.J. Snaith. Nature Photon. 8, 506 (2014).

[11] S. Ahmad, P.K. Kanaujia, H.J. Beeson, A. Abate, F. Deschler, D. Credgington, U. Steiner, G.V. Prakash, J.J. Baumberg. ACS Appl. Mater. Interfaces 7, 25227 (2015).

[12] Z.-K. Tan, R.S. Moghaddam, M.L. Lai, P. Docampo, R. Higler, F. Deschler, M. Price, A. Sadhanala, L.M. Pazos, D. Credgington, F. Hanusch, T. Bein, H.J. Snaith, R.H. Friend. Nature Nano 9, 687 (2014).

[13] S.D. Stranks, H.J. Snaith. Nature Nano 10, 391 (2015).

[14] Y.-H. Kim, H. Cho, J.H. Heo, T.-S. Kim, N. Myoung, C.-L. Lee, S.H. Im, T.-W. Lee. Adv. Mater. 27, 1248 (2015).

[15] F. Li, C. Ma, H. Wang, W. Hu, W. Yu, A.D. Sheikh, T. Wu. Nature Commun. 6, 8238 (2015).

[16] T. Matsushima, S. Hwang, A.S.D. Sandanayaka, C. Qin, S. Terakawa, T.U. Fujihara, M. Yahiro, C. Adachi. Adv. Mater. 28, 10275 (2016).

[17] S.P. Senanayak, B. Yang, T.H. Thomas, N. Giesbrecht, W. Huang, E. Gann, B. Nair, K. Goedel, S. Guha, X. Moya, C.R. Mc Neill, P. Docampo, A. Sadhanala, R.H. Friend, H. Sirringhaus. Sci. Adv. 3, e1601935 (2017).
[18] R. Capelli, S. Toffanin, G. Generali, H. Usta, A. Facchetti, M. Muccini. Nature Mater. 9, 496 (2010).

[19] C. Eames, J.M. Frost, P.R.F. Barnes, B.C. O’Regan, A. Walsh, M.S. Islam. Nature Commun. 6, 7497 (2015).

[20] M.N.F. Hoque, M. Yang, Z. Li, N. Islam, X. Pan, K. Zhu, Z. Fan. ACS Energy Lett. 1, 142 (2016).

[21] E.L. Unger, E.T. Hoke, C.D. Bailie, W.H. Nguyen, A.R. Bowring, T. Heumuller, M.G. Christoforo, M.D. Mc Gehee. Energy \& Environmental Sci. 7, 3690 (2014).

[22] H.-C. Wang, Z. Bao, H.-Yu. Tsai, A.-C. Tang, R.-S. Liu. Small 14, 1702433 (2018).

[23] Y.-H. Kim, H. Cho, T.-W. Lee. PNAS 113, 11694 (2016).

[24] A.N. Aleshin, I.P. Shcherbakov, E.V. Gushchina, L.B. Matyushkin, V.A. Moshnikov. Organic Electron. 50, 213 (2017).

[25] L. Protesescu, S. Yakunin, M.I. Bodnarchuk, F. Krieg, R. Caputo, C.H. Hendon, M.V. Kovalenko. Nano Lett. 15, 3692 (2015).

[26] D.A. Kirilenko, A.T. Dideykin, A.E. Aleksenskiy, A.A. Sitnikova, S.G. Konnikov, A.Ya. Vul'. Micron 68, 23 (2015).

[27] C.D. Dimitrakopoulos, P.R.L. Malenfant. Adv. Mater. 14, 99 (2002).

[28] J. Song, J. Li, X. Li, L. Xu, Y. Dong, H. Zeng. Adv. Mater. 27, 7162 (2015).

[29] Th. Forster. Ann. Phys. 437, 55 (1948).

Редактор К.В. Емцев 